\title{
Do Brine Shrimp Diagnose Cystic Fibrosis?
}

\author{
M. E. HODES, (18) JOHN THOMAS, STEVE MORGAN, AND A. DONALD MERRITT \\ Department of Medical Genetics, Indiana University Medical Center, Indianapolis, Indiana (USA)
}

\begin{abstract}
Extract
The nauplii of the brine shrimp Artemia salina are dependent upon the function of their salt gland to maintain osmotic pressure within narrow limits. A number of drugs interfere with this function and are lethal to the nauplii. Saliva and serum from normal persons, patients with cystic fibrosis, and obligate heterozygotes were tested for lethal effect against brine shrimp nauplii. At salt concentrations between $100 \mathrm{mM}$ and $2.5 \mathrm{M}$ no difference was found among the phenotypes. At lower concentrations a difference was noted occasionally between some normal subjects and some individuals carrying one or two genes for cystic fibrosis. Data from an independent series of experiments indicate that the naupliar deaths result from distorted ratios of $\mathrm{Na}^{+} / \mathrm{K}^{+}$and not from a specific gene product. No difference was noted in the $\mathrm{O}_{2}$ uptake of nauplii treated with saliva or serum obtained from normal subjects, patients with cystic fibrosis, or obligate heterozygotes.
\end{abstract}

\section{Speculation}

The factor in cystic fibrosis that interferes with resorption of sodium from the parotid gland of the rat does not seem to interfere with the larval salt gland of the brine shrimp. Under the conditions tested, this makes it unlikely that brine shrimp can be used to diagnose cystic fibrosis.

After almost 40 years of work the only undisputed, consistent laboratory finding in cystic fibrosis (CF) is an elevation in sweat sodium and chloride $(8,10)$. Although sweat chloride is elevated in persons homozygous for the $\mathrm{CF}$ gene there is no test that will consistently separate heterozygotes (genotype $\mathrm{C} / \mathrm{c}$ ) from patients (genotype $\mathrm{c} / \mathrm{c}$ ) or normal individuals (genotype C/C). Our own interest in tests for detecting heterozygotes stems from our work in counseling families in which this gene is segregating, from our population and genetic linkage studies (2), and from interests in delineating the biochemical defect basic to this disease (6). Preliminary work with the larval form of the brine shrimp, Artemia salina, reported in the accompanying paper (4) indicated that secretions from patients with $\mathrm{CF}$ might interfere with the metabolism of these organisms (5). Our own attempts to develop a test for the CF gene product and the attendant frustrations are reported here.

\section{MATERIALS AND METHODS}

Brine shrimp were obtained, stored, and grown as described by Hootman et al. with some slight modifications suggested by Dr. Conte (7). In experiments with synchronized nauplii, animals hatched between 17 and $19 \mathrm{hr}$ after the start of hydration were utilized.

Probands and their parents were from families under study. All probands had elevated sweat chlorides confirmed in our laboratory. Normal control subjects were volunteers. Genotypes are designated as $\mathrm{C} /$ - (presumed normal, 0.95 probability of $\mathrm{C} / \mathrm{C}$ ): $\mathrm{C} / \mathrm{c}$, obligate heterozygote; $\mathrm{c} / \mathrm{c}, \mathrm{CF}$.
Stimulated parotid saliva or paraffin-gum-stimulated whole saliva was collected in plastic or glass vials. Venous blood was allowed to clot and the serum separated. Saliva and sera were stored at $4^{\circ}$ or $-20^{\circ}$.

Sodium and potassium concentrations were determined by flame photometry or conductance.

Experiments were performed in small $(6 \times 50 \mathrm{~mm})$ culture tubes (11) and in plastic plates with $2-\mathrm{ml}$ cups (12). Whereas only $8-10$ nauplii were used/tube in the preliminary experiments, 50-100 nauplii were placed in each well for the plate experiments, and at least two wells were counted for each concentration of salt or material tested. For ease of presentation only the average figures are given in each table or figure, and only representative data are included. When only survivals after $20-24 \mathrm{hr}$ are revealing, the data obtained at intermediate times are omitted. Evaporation was minimized by placing the plates on a wet towel inside a humid box. The oxygen uptake experiments were performed in a Gilson respirometer (13).

\section{RESULTS}

\section{SURVIVAL EXPERIMENTS IN TUBES}

These experiments are summarized in Table 1. Eight to ten nauplii from 1 to 8 days old were transferred to $50 \mu$ l Instant Ocean Sea Salts (IO) (14) in a small culture tube containing $500 \mu$ l parotid saliva. The number of dead shrimp was recorded every 5 min for 45-60 min. Results were considered positive when half or more of the shrimp were dead by $45 \mathrm{~min}$ and negative when less than half were killed within this span of time.

From the results entered in Table 1 it is apparent that approximately one-half the normal subjects were positive and that there was no consistency in the results obtained from a single individual when he was tested on different occasions. However carriers of the CF gene and CF patients both tested positive more often than did normal subjects. These preliminary results, using only a few nauplii per sample, encouraged us to modify the approach and to engage in large scale experiments in which several conditions were varied, and the ratio of salts controlled. These are described below.

\section{SURVIVAL EXPERIMENTS IN PLATES}

Saliva. In order to minimize the dilution of any active materials in saliva, the effect of salt concentration on the viability of 22-hr-old nauplii was determined after addition of varying amounts of solid $\mathrm{NaCl}$ to $0.4 \mathrm{ml}$ saliva in a 2-ml cup. The shrimp were added to the saline-saliva mixture containing $0.1 \mathrm{ml} 50 \mathrm{mM}$ $\mathrm{NaCl}$. The final concentration of $\mathrm{NaCl}$ was $50-1,000 \mathrm{mM}$. Each experiment was performed in duplicate. The nauplii were observed at $0,30,45$, and $60 \mathrm{~min}$ and after 2, 4, 6, 8, 16, 20, and $24 \mathrm{hr}$. As is obvious from Figure 1, the shrimp fared somewhat better in saliva adjusted to the higher salt concentrations than in the saline solutions without saliva. At $50 \mathrm{mM} \mathrm{NaCl}$ however, the saliva from either the CF patient or a normal control subject was toxic to the 
shrimp, whereas the corresponding saline solution was not. That the toxicity probably resulted from the distorted ratio of $\mathrm{Na}^{+} / \mathrm{K}^{+}$ is apparent from the survivals at $8 \mathrm{hr}$ of nauplii in solutions containing varying amounts of $\mathrm{Na}^{+}$and $\mathrm{K}^{+}$. (Data, provided by Dr. Conte, are presented in Table 2.)

At higher $(1.5-2.5 \mathrm{M})$ concentrations of salt, there was no consistent difference noted between control and CF saliva (Table 3).

In two separate experiments saliva was dialyzed against IO before dilution with IO. There were no differences in deaths at 22-24 hr among $\mathrm{C} /-, \mathrm{c} / \mathrm{c}$, and IO-treated nauplii 30 or 48 hours old (Table 4). There was also no difference noted whether the saliva was diluted to $90 \%$ or $33 \%$ in IO. The state of the specimen (fresh or frozen), the age of the nauplii, and the concentration of the saliva did not affect the results.

Serum. These experiments were performed with serum diluted with saline solution in the presence or absence of IO. The mechanics of the experiments were described above for saliva. Examples of the results obtained in an experiment in which nauplii were treated with $1.5 \mathrm{M} \mathrm{NaCl}$ in the presence or absence of $1 \mathrm{O}$ are summarized in Figure 2. No obvious difference between the presumed normal $(\mathrm{C} /-)$ and $\mathrm{CF}(\mathrm{c} / \mathrm{c})$ individuals is apparent in this test. The age of the nauplii affected their survival but not their ability to discriminate between normal and CF sera. The 22-hr-old nauplii were much less hardy, and either normal or CF sera killed

Table 1. Effects of saliva on nauplii in tubes

\begin{tabular}{|c|c|c|}
\hline \multirow{2}{*}{ Genotype } & \multicolumn{2}{|c|}{ Results of test ${ }^{1}$} \\
\hline & $\begin{array}{l}\text { Multiple tests, } \\
\text { same person }\end{array}$ & $\begin{array}{l}\text { Single test, } \\
\text { different people }\end{array}$ \\
\hline $\mathrm{C} /-$ & $\begin{array}{ll}\text { 1. } & 5+, 3- \\
\text { 2. } & 3+, 3- \\
\text { 3. } & 2+, 1- \\
\text { 4. } & 1+, 1- \\
\text { 5. } & 2-\end{array}$ & $9+, 8-$ \\
\hline $\mathrm{C} / \mathrm{c}$ & $\begin{array}{ll}\text { 1. } 1+, 1- \\
\text { 2. } 4+, 1- \\
\text { 3. } 4+, 1- \\
\text { 4. } 2+ \\
\text { 5. } 2+\end{array}$ & $24+, 5-$ \\
\hline $\mathrm{c} / \mathrm{c}$ & $\begin{array}{ll}\text { 1. } & 3+ \\
\text { 2. } 2+\end{array}$ & $19+, 1-$ \\
\hline
\end{tabular}

${ }^{1}$ Eight to ten nauplii per tube. $+: 50 \%$ or more nauplii dead in $45 \mathrm{~min}$ $-:<50 \%$ dead in $45 \mathrm{~min}$. almost all of the shrimp by the 16th hr of treatment. In the case of the older nauplii, the sera seemed to be protective. The presence of IO resulted in increased survival of older nauplii, particularly when serum was absent (single circled points in figure).

In a final experiment, serum was dialyzed against a solution of $0.1 \mathrm{M} \mathrm{NaCl}$ and $0.004 \mathrm{M} \mathrm{KCl}$, or against IO, or used undialyzed but slightly diluted by the solution used to transport the nauplii. The sera were used to treat 24 -hr-old nauplii. No consistent differences among genotypes were noted at any of the electrolyte concentrations (Table 5). These experiments rule out age of nauplii and presence or absence of $1 \mathrm{O}$ as factors in the results.

\section{EFFECT OF CF SALIVA AND SERUM ON $\mathrm{O}_{2}$ UPTAKE}

The experiments were performed in a differential respirometer (10). Each $25-\mathrm{ml}$ flask contained a $\mathrm{KOH}$ wick in the inner well and

Table 2. Effect of $\mathrm{Na}^{+}$and $\mathrm{K}^{+}$on survival of nauplii at $8 \mathrm{hr}$

\begin{tabular}{rrrrrrrrr}
\hline & \multicolumn{8}{c}{ \% alive with varied K concentrations $(\mathrm{mM})$} \\
\cline { 2 - 9 } $\mathrm{Na}, \mathrm{mM}$ & \multicolumn{1}{c}{0} & \multicolumn{1}{c}{10} & 10 & 12 & 14 & 16 & 18 & 20 \\
\hline 0 & 13 & 3 & & & & & & \\
5 & 12 & & & & & & & \\
10 & 29 & 1 & & & & & & \\
20 & 89 & 70 & 32 & & & & & \\
30 & 98 & 100 & 87 & 75 & 20 & & 15 & \\
50 & 100 & 100 & 100 & 100 & 100 & 33 & 58 & 16 \\
100 & 99 & 98 & 97 & 104 & 103 & 102 & 100 & 100 \\
\hline
\end{tabular}

Table 3. Effect of genotype and elevated salt concentration on survival of nauplii treated with saliva in open $2-\mathrm{ml}$ wells in plastic plates

\begin{tabular}{|c|c|c|c|}
\hline \multirow[b]{2}{*}{ Genotype } & \multicolumn{3}{|c|}{$\%$ dead at $20 \mathrm{hr}$, varied $\mathrm{NaCl}$} \\
\hline & $1.5 \mathrm{M}$ & $2.0 \mathrm{M}$ & $2.5 \mathrm{M}$ \\
\hline
\end{tabular}

$\begin{array}{cc}\mathrm{C} /- & \\ I & 12 \\ 2 & 12 \\ 3 & 19 \\ \mathrm{c} / \mathrm{c} & \\ I & 21 \\ 2 & 52 \\ 3 & 21 \\ \text { Saline } & 18\end{array}$

16
19
37
21
32
17
31

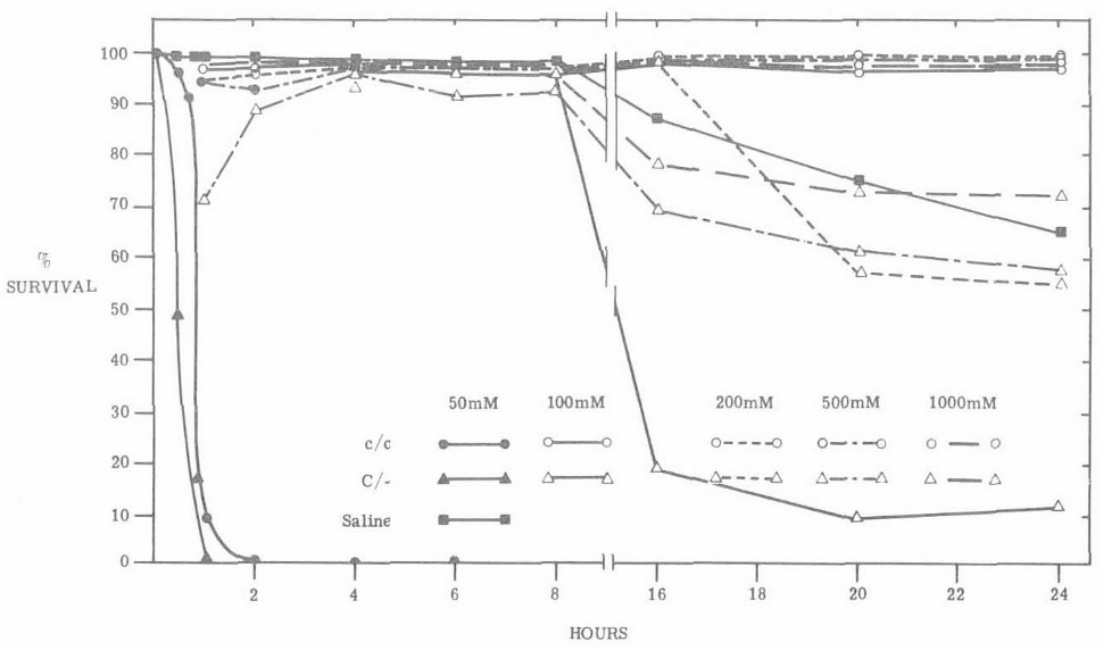

Fig. 1. The effect of cystic fibrosis genotype and salt concentration on the survival of 22-hr-old nauplii treated with saliva. 
$500-2,000$ nauplii in $3 \mathrm{ml}$ liquid in the outer well. The liquid phase was either a $2: 1$ mixture of whole saliva or serum-IO or that mixture fortified with salt to a final concentration of $0.5 \mathrm{M} \mathrm{NaCl}$. $\mathrm{O}_{2}$ uptake was measured over a 2-12-hr period after preliminary equilibration. Controls consisted of nauplii in IO alone or with the addition of $\mathrm{KCl}$ or ouabain. The data from three experiments are presented in Table 6. As is apparent from the results of the experiments, there was no significant difference in $\mathrm{O}_{2}$ uptake between control (IO only) or test (IO + saliva) samples. Older nauplii took up more oxygen, and as expected, both $\mathrm{KCl}$ and ouabain decreased $\mathrm{O}_{2}$ uptake. In addition to those shown in Table 6 ,

Table 4. Effect of genotype on survival of nauplii of different ages treated with different concentrations of saliva in open 2-ml wells in plastic plates

\begin{tabular}{cll}
\hline & \multicolumn{2}{c}{ \% dead at 22-24 hr } \\
\cline { 2 - 3 } & $\mathrm{C} /-$ & $\mathrm{c} / \mathrm{c}$ \\
\hline $33 \%$ saliva & & \\
30 -hr nauplii & & \\
$I^{1}$ & 1 & 4.5 \\
2 & 0 & 4.5 \\
3 & 2.5 & 8 \\
$4^{2}$ & 3.5 & 4.5 \\
5 & 4 & 5 \\
6 & 4 & 5.5 \\
7 & 3 & \\
8 & & 3.5 \\
48 -hr nauplii & 0 & 0 \\
$l^{2}$ & 1 & 1.5 \\
3 & 1 & 1 \\
$90 \%$ saliva & & 2 \\
$l^{3}$ & 4 & 3 \\
2 & 2.5 & 0 \\
3 & 3.5 & 2 \\
4 & 3.5 & \\
5 & 1.5 &
\end{tabular}

\footnotetext{
${ }^{1}$ Frozen (specimens $\left.1-3\right)$.
}

${ }^{2}$ One day or less (specimens $4-8$ ).

${ }^{3}$ All specimens stored in refrigerator 2-3 days and dialyzed against Instant Ocean Sea Salts (IO) before dilution with IO. data were obtained from additional experiments with small numbers of samples, three of saliva and one of serum. In the experiments with saliva, $\mathrm{O}_{2}$ uptake by 24 -hr-old nauplii was measured at $25^{\circ}$ or $35^{\circ}$. No decreases in $\mathrm{O}_{2}$ uptake were noted when any of the genotypes were employed in either the saliva or serum experiments. In all the experiments treatment with $\mathrm{KCl}$ markedly decreased $\mathrm{O}_{2}$ uptake. The consumption of oxygen was generally greater in the presence of saliva than in its absence. There was no correlation between genotype and survival of nauplii at the end of the experiments.

\section{DISCUSSION}

Larval brine shrimp possess a neck organ that functions as a salt pump (3). Certain cardiac glycosides interfere with the action of this pump (5). Thus it seemed logical to suspect that other factors interfering with the transport of electrolytes might also interfere with the function of the neck organ. Because saliva and serum of patients with $\mathrm{CF}$ are reported to contain a substance or substances that interfere with sodium resorption in the parotid gland of the rat (9), it was decided to test these fluids against brine shrimp. In preliminary experiments (data not shown) no difference was noted when tests were performed in saliva obtained from any of the

Table 5. Effect of genotype and salt concentration on survival of nauplii treated with serum in open $2-\mathrm{ml}$ wells in plastic plates ${ }^{1}$

\begin{tabular}{|c|c|c|c|c|}
\hline \multirow{2}{*}{$\begin{array}{c}\text { Final salt } \\
\text { concentration in serum }\end{array}$} & \multicolumn{3}{|c|}{$\%$ dead at $26 \mathrm{hr}$} & \multirow{2}{*}{$\begin{array}{l}\text { Saline } \\
\text { control }\end{array}$} \\
\hline & $\mathrm{C} /-$ & $\mathrm{C} / \mathrm{c}$ & $\mathrm{c} / \mathrm{c}$ & \\
\hline \multicolumn{5}{|l|}{$\mathrm{Na}^{+}=100 \mathrm{mM}, \mathrm{K}^{+}=4 \mathrm{mM}^{2}$} \\
\hline 1 & 18 & 33 & 38.5 & 90 \\
\hline 2 & 32 & 34.5 & 34.5 & \\
\hline \multicolumn{5}{|c|}{$\mathrm{Na}^{+}=475 \mathrm{mM}, \mathrm{K}^{+}=16 \mathrm{mM}^{2,3}$} \\
\hline 1 & 2.5 & 3.5 & 3.5 & 0.5 \\
\hline 2 & 0 & 0.5 & 0 & \\
\hline \multicolumn{5}{|l|}{$\mathrm{Na}^{+}=112 \mathrm{mM}, \mathrm{K}^{+}=3.6 \mathrm{mM}^{4}$} \\
\hline 1 & 10 & 9.5 & 11 & \\
\hline 2 & 12 & 8 & 6.5 & \\
\hline
\end{tabular}

${ }^{1}$ All specimens were refrigerated 1 day prior to test.

${ }^{2}$ Dialyzed.

${ }^{3}$ Instant Ocean Sea Salts.

${ }^{4}$ Not dialyzed.

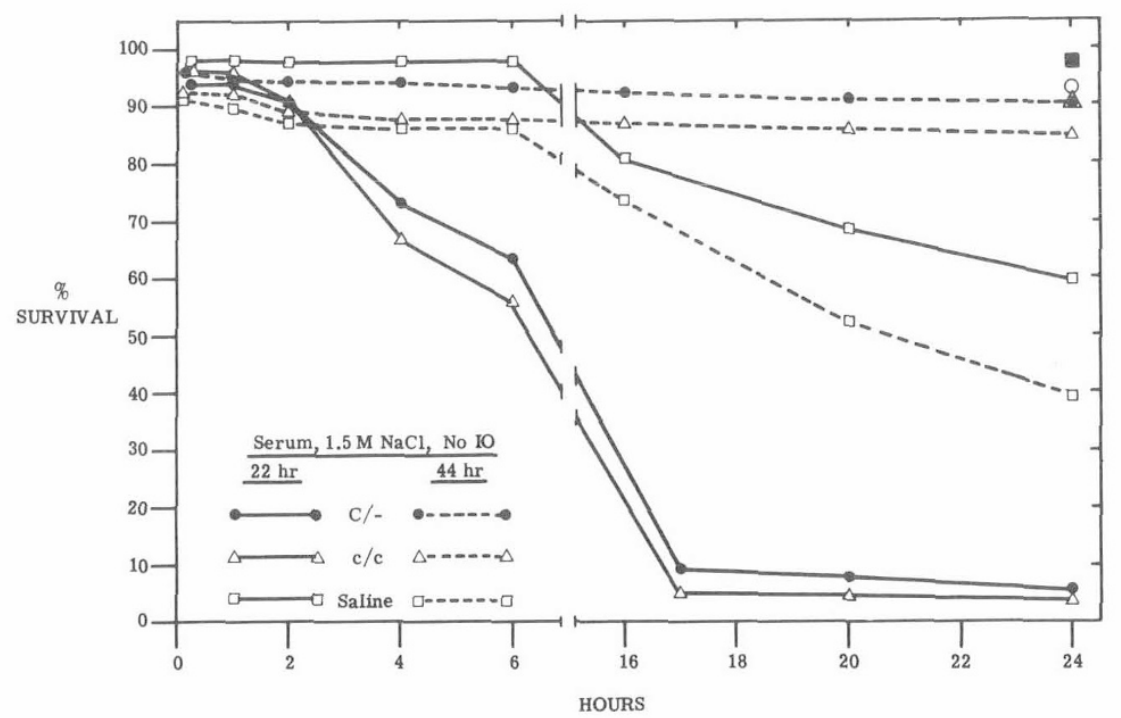

Fig. 2. The effect of cystic fibrosis genotype on the survival of 22- and 44-hr-old nauplii treated with serum in $1.5 \mathrm{M} \mathrm{NaCl}$. No IO: no Instant Ocean Sea Salts. 
Table 6. Uptake of $\mathrm{O}_{2}$ by nauplii

$\mathrm{O}_{2}$ consumption $\left(\mu \mathrm{l} \mathrm{O}_{2} / \mathrm{hr} \times\right.$ nauplius $)$

No.

Genotype

specimens

$4 \mathrm{hr}$

$6 \mathrm{hr}$

$10 \mathrm{hr}$

I. Saliva sea salts, 2:1 $(0.19 \mathrm{M}$

$\mathrm{NaCl}$ ); 24-hr-old nauplii, $30^{\circ}$

$\mathrm{c} / \mathrm{c}$

$\mathrm{C} / \mathrm{c}$

$\mathrm{C} /-$

Sea salts

$\mathrm{KCl}$

$2 \mathrm{hr}$

$0.034 \pm 0.0037$
$0.031 \pm 0.0026$
$0.036 \pm 0.0062$
$0.028 \pm 0.0000$
$0.010 \pm 0.0000$

$0.055 \pm 0.0007$

$0.056 \pm 0.0023$

$0.052 \pm 0.0025$

$0.030 \pm 0.0000$

$0.017 \pm 0.0000$

$0.041 \pm 0.0000$

$\begin{array}{ll}0.034 \pm 0.0039 & 0.037 \pm 0.0047 \\ 0.032 \pm 0.0036 & 0.033 \pm 0.0046 \\ 0.038 \pm 0.0059 & 0.039 \pm 0.0058 \\ 0.028 \pm 0.0000 & 0.029 \pm 0.0000 \\ 0.007 \pm 0.0000 & 0.006 \pm 0.0000\end{array}$

$0.055 \pm 0.0006$

$0.056 \pm 0.0017$

$0.052 \pm 0.0031$

$0.037 \pm 0.0000$

$0.015 \pm 0.0000$

$0.045 \pm 0.0000$
$0.055 \pm 0.0006$

$0.056 \pm 0.0017$

$0.040 \pm 0.0000$

$0.014 \pm 0.0000$

$0.046 \pm 0.0000$
$0.053 \pm 0.0032$

$\left(1 \times 10^{-4} \mathrm{M}\right)$

III. Saliva sea salts, 2:1 (0.5 M NaCl);

20-hr-old nauplii, $30^{\circ}$

$\mathrm{c} / \mathrm{c}$

$\mathrm{C} / \mathrm{c}$

$0.047 \pm 0.0040^{1}$

$0.042 \pm 0.0030^{1}$

$0.042 \pm 0.0020^{1}$

$0.037 \pm 0.0000^{1}$

Sea salts

$0.036 \pm 0.0000^{1}$

$0.072 \pm 0.0050^{2}$

$0.056 \pm 0.0060^{2}$

$0.059 \pm 0.0175^{2}$

$0.051 \pm 0.0000^{2}$

$0.037 \pm 0.0000^{1}$

$\left(2 \times 10^{-4} \mathrm{M}\right)$

${ }^{1}$ Measured between 4 and $6 \mathrm{hr}$.

${ }^{2}$ Measured between 10 and $12 \mathrm{hr}$.

genotypes adjusted to $0.15 \mathrm{M}$ concentration of $\mathrm{NaCl}$. Attempts were then made to stress the shrimp by varying the salt concentration. At low concentrations approximating those found in saliva, shrimp were regularly killed by CF saliva and often by normal saliva. In a separate series of experiments this killing was found to be a function of the ratio of $\mathrm{Na}^{+} / \mathrm{K}^{+}$rather than the origin of the saliva specimen. Both ions must be present and in certain proportions to assure maximum survival, especially over extended periods of time. However, at concentrations of $\mathrm{Na}^{+}$greater than $100 \mathrm{mM}$ the concentrations of $\mathrm{K}^{+}$found in saliva exerted no material influence on the survival of shrimp in control experiments (no saliva present). Therefore a series of experiments was performed in which the concentration of $\mathrm{Na}^{+}$was adjusted to $100 \mathrm{mM}$ or greater. The bulk of the experiments reported above show that at concentrations of $\mathrm{Na}^{+}$ranging from 50 to $2,000 \mathrm{mM}$ brine shrimp survive equally well in saliva derived from normal and CF individuals.

Several factors may account for these results. During the development of the brine shrimp control of osmotic pressure passes from the neck organ to the leg segments. The gut is not developed at hatching but forms in $48 \mathrm{hr}$, after which the nauplii begin to feed. These changes affect both the normal handling of salt and water by the shrimp and possible areas of contact between the organism and the saliva or serum used in these tests. For these reasons tests were performed with shrimp of different ages. The outcome was the same regardless of the age of the nauplii, and whether they were capable of feeding or not.

In an abstract it was reported recently that saliva of CF patients inhibits the uptake of $\mathrm{O}_{2}$ by nauplii (1). The experiments reported here fail to confirm that finding. In the absence of details on methodology, we can only speculate on the reasons for the discrepancy.

The results of a series of experiments in which saliva, serum, salt concentration and age of nauplii were varied have not led to development of a means to distinguish between patients with cystic fibrosis, their parents, and normal individuals.

\section{SUMMARY}

In an attempt to develop an assay for the product of the gene for cystic fibrosis and thus a way of detecting carriers of the disorder, nauplii of the brine shrimp Artemia salina were exposed to serum and saliva from affected patients, their parents, and normal individuals. When the criterion was naupliar survival, neither serum nor saliva from normal subjects, obligate heterozygotes, or affected individuals had a striking effect when observed over a 20-24-hr period in the presence of various concentrations of sodium chloride. Varying the age of the nauplii from 20 to $48 \mathrm{hr}$ was also without effect. Several experiments with nauplii of different ages failed to show any consistent interference with oxygen uptake. It was concluded that under the conditions tested, brine shrimp larvae could not be used to distinguish the cystic fibrosis phenotypes from each other or from normal subjects.

\section{REFERENCES AND NOTES}

1. Bargman, G. J., and Weisz, L.: Cystic fibrosis (CF) and respiratory energy production. Pediat. Res., 8: 464 (1974).

2. Conneally, P. M., Merritt, A. D., and Yu, P.-L.: Cystic fibrosis: Population genetics. Texas Rep. Biol. Med., 31: 639 (1973).

3. Conte, F. P., Hootman, S. R., and Harris, P. J.: Neck organ of Artemia salina nauplii: A larval salt gland. J. Comp. Physiol., 80: 239 (1972).

4. Conte, F. P., Ewing, R. D., Hodes, M. E., and Merritt, A. D.: Cystic fibrosis: Possible toxic factor of ion regulation and ATP synthesis in larval brine shrimp. Pediat. Res. (In press).

5. Ewing, R. D., Peterson, G. L., and Conte, F. P. Larval salt gland of Artemia salina nauplii. Effect of inhibitors on survival at various salinities. J. Comp. Physiol., 80: 247 (1972).

6. Hodes, M. E., Merritt, A. D., and Glier, J. T.: An evaluation of differential methylation of ribonucleic acid in cystic fibrosis. Pediat. Res., 8: 212 (1974).

7. Hootman, S. R., Harris, P. J., and Conte, F. P.: Surface specialization of the larval salt gland in Artemia salina nauplii. J. Comp. Physiol. 79: 97 (1972).

8. Lobeck, C. C.: Cystic fibrosis. In: J. B. Stanbury, J. B. Wyngaarden, and D. S. Fredrickson: The Metabolic Basis of Inherited Disease, p. 1619 (McGraw-Hill, New York, 1972).

9. Mangos, J. A., McSherry, N. R., and Benke, P. J.: A sodium transport inhibitory factor in the saliva of patients with cystic fibrosis of the pancreas. Pediat. Res., 1: 436 (1967) 
10. Shwachman, H.: Changing concepts of cystic fibrosis. Hosp. Pract., January: 143 (1974).

11. Exax 45060, Kimble, Owens-Illinois, Inc., Toledo, Ohio.

12. Model 96CV-Clear, Linbro Chemical Co., Inc., New Haven, Conn.

13. Gilson Medical Electronics. Middleton, Wisc.

14. Aquarium Systems, Inc., Eastlake, Ohio.

15. The assistance of Alice Pigg, Marianne Karn, and Joann Stafford in collecting the specimens is gratefully acknowledged. We are indebted to Dr. Frank P Conte of Oregon State University for the data of Table 2.
16. Drs. Hodes and Merritt were supported in part by grants from the J. W. Riley Memorial Association and Public Health Service Research Grants AM 13428 and GM 21054 .

17. John Thomas was supported by National Institutes of Health Training Grant GM 1056.

18. Requests for reprints should be addressed to: M. E. Hodes, M.D., Ph.D. Department of Medical Genetics, Indiana University School of Medicine, 1100 W. Michigan St., Indianapolis, Ind. 46202 (USA).

19. Accepted for publication May 9, 1975.

\title{
Glucose Production in the Newborn Dog. I. Effects of Glucagon in Vivo
}

\author{
PETER A. J. ADAM, GARY GLAZER, AND FREDERICK ROGOFF \\ Department of Pediatrics, Case Western Reserve University School of Medicine at Cleveland Metropolitan General Hospital, \\ Cleveland, Ohio (USA)
}

\section{Extract}

Systemic glucose production rates were evaluated $4 \mathrm{hr}$ after feeding in 14 newborn beagle dogs at ages between 1 and 5 days. After a prime injection of radioisotopic tracers, glucose production was determined during infusion of intermixed tracer $\left[2-{ }^{3} \mathrm{H}\right]$ glucose and $\left[1-{ }^{14} \mathrm{C}\right]$ glucose at a constant rate. Seven of the newborn dogs served as controls throughout the 3 -hr period of infusion, while seven of their littermates, infused simultaneously, received glucagon at a constant rate of $3.3 \mu \mathrm{g} / \mathrm{min}$ between 90 and $180 \mathrm{~min}$ of study. In control dogs, mean glucose production, determined by dilution of $\left[2-{ }^{3} \mathrm{H}\right]$ glucose, was $55 \pm 3 \mu \mathrm{mol} / \mathrm{min} \cdot \mathrm{kg}$ body weight. During the control period, their littermates produced glucose at a similar rate; however, glucagon infusion raised glucose production to $81 \pm 4$ $\mu \mathrm{mol} / \mathrm{min} \cdot \mathbf{k g}$.

The average glucose production rate estimated with $\left[1-{ }^{14} \mathrm{C}\right]$ glucose was $88 \%$ of that with the ${ }^{3} \mathrm{H}$ tracer during the initial control period and $77 \%$ during the glucagon infusion. In order to confirm that this discrepancy reflected the recycling of ${ }^{14} \mathrm{C}$ and the early development of gluconeogenesis, an additional 14 newborn dogs were infused with potential substrates for $\left[{ }^{14} \mathrm{C}\right]$ glucose. In separate studies, $\left[U-{ }^{14} \mathrm{C}\right]$ lactate, $\left[3-{ }^{14} \mathrm{C}\right]$ lactate, $\left[U-{ }^{14} \mathrm{C}\right]$ alanine, and $\left[6-{ }^{14} \mathrm{C}\right]-$ glucose were incorporated into glucose and $\left[1-{ }^{14} \mathrm{C}\right]$ glucose. Quantification of gluconeogenesis by simultaneous infusion of $\left[6-{ }^{3} \mathrm{H}\right] \mathrm{glu}-$ cose and $\left[3-{ }^{14} \mathrm{C}\right]$ lactate in a 5-day-old dog demonstrated that $25 \%$ of the glucose produced originated from lactate, whereas $10 \%$ was incorporated into carbon 1 . Thus, systemic glucose production was established rapidly in newborn dogs and responded to stimulation with glucagon. A significant proportion of the glucose originated from recycling via the gluconeogenic pathway.

\section{Speculation}

Even in well nourished newborn mammals, recycling of glucose is important in maintaining homeostasis during the postabsorptive period. Based on comparisons between dogs infused with [3$\left.{ }^{14} \mathrm{C}\right]$ lactate or $\left[6-{ }^{-14} \mathrm{C}\right]$ glucose, $25 \%$ or more of hepatic glucose production may originate from glucose recycled through lactate and pyruvate. Presumably most of the rest is derived from hepatic glycogen stored in utero.
Shortly after separation from the maternal glucose supply, a newborn animal must establish hepatic and perhaps renal glucose production in order to maintain the blood glucose at physiological levels (1). In the fasting newborn infant or mammal, plasma insulin remains at relatively low levels, whereas plasma glucagon levels rise $(8,13)$. Since the normal newborn infant or mammal is able to stabilize the blood glucose concentration shortly after birth, normoglycemia is attributed to stimulation of hepatic glucose production by a preponderance of glucagon over insulin effect.

Hepatic glucose production has been quantified previously in newborn dogs utilizing uniformly labeled $\left[{ }^{14} \mathrm{C}\right]$ glucose (11) or $\left[2{ }^{3} \mathrm{H}\right]$ glucose as a tracer $(15)$. In studies of adult dogs, however, uniformly labeled glucose has underestimated systemic glucose production rates (10), particularly in the presence of hormonal stimulation with methylprednisolone. The presumed reason for this reduced estimate is recycling of ${ }^{14} \mathrm{C}$ in glucose.

Such recycling in the newborn would depend on development of enzymatic activities associated with gluconeogenesis. In recent studies hepatic fructose diphosphatase, phosphoenolpyruvate carboxykinase, and mitochondrial pyruvate carboxylase activities rise to physiological levels within the first day after birth $(4,5)$. Thus, the potential for recycling exists, could cause underestimation of neonatal glucose production, and may contribute substantially to glucose homeostasis.

The potential for hormonal control of hepatic glucose production by insulin, pancreatic glucagon, and splanchnic neural norepinephrine has been evaluated in vivo and in vitro in newborn dogs. From $4.5 \mathrm{hr}$ to 55 days of age, infusion of glucose alone or with physiological quantities of insulin suppresses glucose production in young dogs ineffectively compared with adults, indicating "resistance" to insulin action (15). Pharmacological quantities of glucagon in vivo raise systemic glucose production 36\% during [U${ }^{14} \mathrm{C}$ ]glucose infusion (11), whereas norepinephrine, $10^{-6} \mathrm{M}$, in vitro, raises glucose production by the isolated perfused liver $71 \%$ above control levels $(4,5)$. The response to glucagon $10^{-6} \mathrm{M}$ in vitro is of a similar magnitude (4).

The present study was done to quantify hepatic glucose production, gluconeogenesis, and recycling of glucose in the newborn dog. In addition the effects of pharmacological doses of glucagon were 